
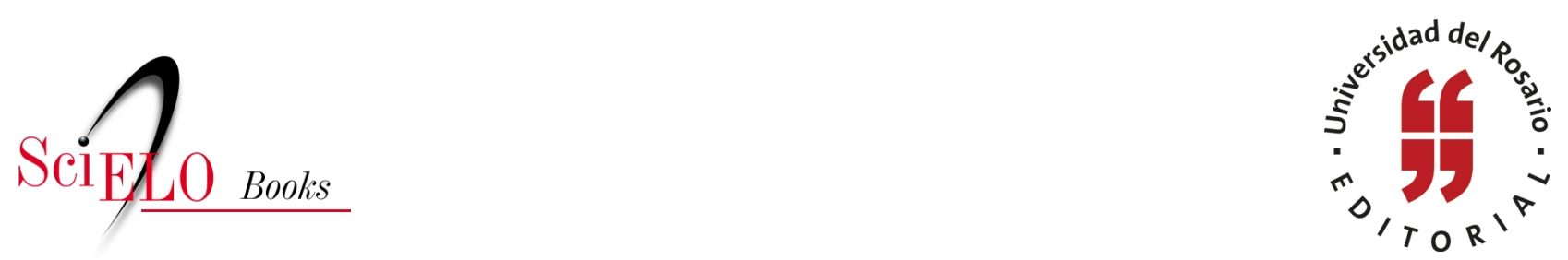

\title{
23. Esfuerzo propio
}

\author{
César Augusto Tapias Hernández
}

\section{SciELO Books / SciELO Livros / SciELO Libros}

TAPIAS HERNÁNDEZ, C.A. Esfuerzo propio. In: Historias de familia: Etnografía delirante sobre el amor, la violencia y las drogas [online]. Bogotá: Editorial Universidad del Rosario, 2014, pp. 97-100. Textos de ciencias humanas collection. ISBN: 978-958-738-543-4. https://doi.org/10.7476/9789587385434.0024.

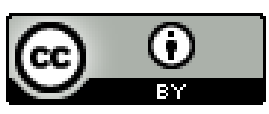

All the contents of this work, except where otherwise noted, is licensed under a Creative Commons Attribution 4.0 International license.

Todo o conteúdo deste trabalho, exceto quando houver ressalva, é publicado sob a licença Creative Commons Atribição $\underline{4.0}$.

Todo el contenido de esta obra, excepto donde se indique lo contrario, está bajo licencia de la licencia $\underline{\text { Creative }}$ Commons Reconocimento 4.0 . 


\section{Esfuerzo propio}

Pensó: "Son las gentes más enigmáticas del planeta... Educadas para aceptar lo que la vida les traiga, sea bueno, malo o atroz". Mario Vargas Llosa, La guerra del fin del mundo

-Fuimos nosotros los que nos los trajimos a toda la familia desde Titiribí. Jaime recién salido del Ejército, Oliva trabajando en la Noel, y yo en una casa de familia donde estuve por lo menos diez años. Hasta el 2 de febrero de 1964 cuando empecé a trabajar en el municipio...

Llegaron primero a Itagüí, luego a Envigado. Mi mamá estaba muy pequeña cuando eso. Ella es la menor de la casa de los Fernández. Que dizque se hacía en una piedra que había ahí enfrente de la casa, no más que a gritar:

—¿Quién quiele “jular”, quién quiele "jular”, yo “juelo”? (Por decir que quién quería jugar con ella)

A estas alturas, ya muchos en la familia conocen las intenciones de recolectar estas historias: armar un álbum, un libro, un inventario. Y no diré que le resta interés el que la gente lo sepa; pero sí es seguro que se crean muchas más expectativas. Y hablo pensando en todos aquellos que tienen algo que contar... y que ahora, de un momento a otro, lo quieren contar...

-A través de don Guillermo Villegas, un antiguo patrón, conseguimos la casa en El Pedregal. Era cuestión de conseguir un formulario para el Instituto de Crédito Territorial y llenarlo. Aunque se hizo, yo no le paré muchas bolas a eso hasta que tío Toño fue por allá al edificio del teatro Junín, donde hoy es el Coltejer, y vio el nombre de Laura Quiroz... Él sí dijo que miráramos por allá, que quién sabía que de pronto sí era pa’ nosotros, y sí... así fue: salimos seleccionados y el lote que nos tocó quedaba por allá donde vive la familia de su papá, ¿La Tinaja...? Por esa cuadra, pero mi papá y don Guillermo dijeron que no. Que eso era muy alto y muy solo. Que 
era un solo pedrero... Entonces conseguimos uno como más central. En esa época, por la cuadra que nos tocó apenas éramos nosotros y la familia de Miriam Lotero. - ¿Por qué apareció aquello a nombre de mamita Laura y no tuyo, si el formulario te lo dieron a vos?

— ¡Porque yo no estaba casada!

¡Y nunca lo estuvo! A mi tía Carmen Fernández Quiroz, mujer desafiante para la época, la mayor de la casa de los Fernández, además verraca por lo que verán... le tocó soportar durante varios meses el silencio del abuelo Gabriel, quien no le determinaba ni a ella ni a Omaira, que porque a Carmen la tuvo sin haberse casado.

- Se hicieron los papeles y mi papá empezó a construir...

— ¿Él solo o alguno de los muchachos le ayudaban?

- Jaime era el que le ayudaba. Gildardo estaba muy pequeño y a lo mejor sí puso unas piedritas por ahí, pero también había uno que otro trabajador.

Lo del Instituto de Crédito Territorial no era solo un lote ahí; era también un préstamo con el que se retiraban los materiales; la construcción sí era un esfuerzo propio; así incluso era como se conocía el programa de autoconstrucción. Y el papito Gabriel se quedaba hasta los ocho días de la semana trabajando en la casa de El Pedregal.

-Pa' que se iba a volver hasta Envigado...

- ¿Ya papito no trabajaba en alguna otra parte o qué?

-No, ya que le iban a dar trabajo a esa edad...

- ¿Y el negocio que tenía en la América, con el tío Jaime? — pregunta Omaira.

-Eso fue ya estando aquí... Era que su tío Jaime se lo manejaba, sino estoy mal...

Don Guillermo Villegas, una persona bien recordada por la tía Carmen, se había comprado un terreno por los lados del corregimiento de San Cristóbal, por donde quedaba la casa de Montecristo, y tumbó la casa que había ahí para hacerse otra. Todo lo que iba sacando y que servía, lo iba mandando pa' la casa de la familia de Carmen en El Pedregal. La tía recuerda sin hacer mucho esfuerzo que fue don Guillermo quien le habló al doctor Londoño, que tenía un hermano por allá en una fábrica de baldosas... Mosaicos:

-A ver sí me entregaban unas baldosas y yo pagaba con el sueldo, eso lo negoció fue don Guillermo, o que él las pagaba o que él mismo se encargaba de sacarme de mi sueldo algo. No de una, porque yo tenía que ayudar en la casa; pero que eso se pagaba y él respondía por si algo... 
- ¿Eh, y vos es que cotizabas con don Guillermo o qué tía, por que qué señor más querido, o no?

-Noooooooooooooo, qué va. Yo sí tenía un novio y fue él quien pegó las baldosas en la casa, porque es que siempre me las dieron. De segunda, casi regaladas... pero es mejor deber plata que favores. ¡Donde don Guillermo Villegas no me liquidaron! ¿Cómo iba yo a pedir plata después de todo lo que me ayudaron: la casa, el trabajo pa' los muchachos...? Porque lo que fue Iván y Jaime resultaron trabajando el Peldar, Gildardo por lo que estaba tan muchacho resultó pa' mensajero en una empresa... Y así...

—Y si el tío Iván se vino para acá también, ¿entonces cuándo arrancó para Segovia?

-Él se vino ya casado, pero esa mujer que tenía sufría mucho de unos cólicos que, mejor dicho, a veces caía como un pollo. Entonces Iván todo aburrido. Un día, el suegro se lo llevó pa’ Megachí, o algo así —Vegachí, mamá, aclaró Omaira-. Y entonces se quedó en la montaña hasta ahora que se volvió y eso por los problemas que tuvo con la guerrilla, si no, allá estuviera.

— ¿Y, el papito, cuándo fue que resolvió irse para Nueva Jersey?

-Ya estábamos en la casa de El Pedregal, y Oliva ya se había organizado bien en los Estados Unidos. Papá se fue para donde ella y se estuvo cinco años.

—¿En qué trabajaba si estaba de edad? - Se inquieta Nando, el marido de Omaira.

— ¡Empacando mercancías! — Responde la tía, agregando, que la mamita Laura nunca fue allá porque nunca le dieron la visa.

-Y ya que hablás de mamita Laura, ¿qué es lo que más recordás de ella?

- Qué recuerdo yo de ella... Que era muy rezandera.

Todos los primeros viernes de cada mes, mamita Laura bajaba al pueblo a la jornada de oración del Corazón de Jesús. Salía a eso de las cinco de la mañana, cuando ya aclaraba el día. Se tardaba tres horas en llegar al pueblo para la misa de las ocho de la mañana y como eran tan pobres de dinero, a veces ni pa'l tinto tenía, y no más pasaba con un vaso de agua.

- ¿Y qué?, ¿era regañona la abuelita Laura?

— ¿No!, de pronto le hacíamos un motivo y nos quedamos en la calle hasta que llegara papá y así no nos pegaba.

Un día, la tía Emma, el tío Iván y Carmen, que eran los mayores, aprovecharon que mamita Laura le llevó el almuerzo a papito Gabriel: se sacaron un tabaco 
de los de don Gabriel. Al viejo, como le gustaba fumarse uno que otro de esos, y se metieron tremenda borrachera...

—Cuando llegó mamá, nosotros estábamos más malucos que un diablo. Y mi papá que se da cuenta que le faltaban tabacos. Entonces, va y pregunta por los que faltan. Debimos fumarnos varios porque pa' la borrachera y pa' que él se diera cuenta... En fin, mamá dijo que no sabía nada; pero se acordó de nosotros y dijo que... a lo mejor habíamos sido nosotros, que porque cuando ella había llegado de llevarle el almuerzo, nosotros estábamos vomitando. De la rasca, sería...

La tía Carmen se llenó de sentimiento al recordar lo acontecido en torno a la construcción de la casa en El Pedregal. No olvida al papito Gabriel cuando la acompañaba prácticamente hasta la autopista donde tenía que tomar buses de Bello o Copacabana para poder llegar al centro de la ciudad, y ella alzaba un pie para subir al bus y papito le ponía un zapato limpio, igual con el otro pie. Todo El Pedregal era un pantanero sin precedentes hasta la autopista Medellín-Bogotá, y solo cuando había verano, los carros arrimaban hasta donde empezaba el barrio... El agua debían sacarla de una pila que quedaba un tanto más lejos; por ahí donde quedaba también la capilla. Papito Gabriel tenía que madrugar como a las tres de la mañana si quería agua. En El Pedregal ya había mucha gente soñando con el progreso.

Esa casa finalmente tuvo que ser vendida, muertos los abuelos. Mi tía Carmen confiesa que prefiere no pasar por allí. Ya tiene dos pisos, cuando a ellos jamás les interesó construir más. Esa casa era grande. Recuerdo que tenía cuatro habitaciones, dos patios, una cocina grandecita, también con vista al patio y a la tarde...; el pasillo: un zaguancito y una piecita junto a los baños. Pero, más que el espacio, el sol sobre las botellas verdes de gaseosas Castalia, Gilda con su bata de baño cepillándose los dientes en el patio, desearía recordar más a la abuela: su cabello largo, muchas veces adornado con trenzas, su paso lento por su casa larga desde el jardín hasta el patio de atrás... Y al papito Gabriel... papito terminó por poner una tienda pequeña de la que solo recuerdo las Castalias y los chicles globo. Pasó el tiempo, y en sus últimos días terminé buscándole yerbas de no sé qué cosa, para unos baños que le preparaba mamá. Baños de agua tibia y yerbas verdes para sus piernas cansadas e hinchadas de andar el mundo. Mi abuelo fue hasta Nueva York desde Titiribí, igual que hoy hace el tío Mario...

Carmen siguió siendo centro de afectos y encuentros durante muchos años.... Como siendo una versión renovada de doña Laura. Hoy habita nuestro recuerdo... Se ha convertido en una estrella. 